\title{
Opportunities and perspectives for developing orexin receptor antagonists
}

\author{
Michel A. Steiner ${ }^{1 *}$ and Christopher J. Winrow ${ }^{2}$ \\ 'Actelion Pharmaceuticals Ltd., Department of Central Nervous System (CNS) Pharmacology, Allschwil, Switzerland \\ ${ }^{2}$ Merck Research Laboratories, Department of Neuroscience, West Point, PA, USA \\ *Correspondence: michel.steiner@actelion.com
}

Edited and reviewed by:

Nicholas M. Barnes, University of Birmingham, UK

Keywords: orexin, hypocretin, neuropeptide, orexin receptor antagonist, insomnia, anxiety, addiction, neuroscience

The current special topics issue of Frontiers in Neuroscience "Insomnia and Beyond-Exploring the Therapeutic Potential of Orexin Receptor Antagonists" comprises 20 papers from leaders in the orexin/hypocretin field presenting their latest findings and thorough reviews, and will undoubtedly serve as an important reference for others engaged in this field of study. Since the independent identification of the orexin/hypocretin system in 1998 by two teams investigating hypothalamic signaling (de Lecea et al., 1998; Sakurai et al., 1998), the field has rapidly expanded to include potential roles of orexin in processes as diverse as sleep/wake, addiction, feeding, pain and anxiety. Orexin neuropeptides (OX-A, OX-B) are cleaved from a common precursor and secreted from orexinergic neurons localized in the lateral hypothalamus. Orexins (also passionately referred to as hypocretins by many investigators) bind and activate two G-protein coupled receptors $\left(\mathrm{OX}_{1} \mathrm{R}\right.$ and $\left.\mathrm{OX}_{2} \mathrm{R}\right)$, with $\mathrm{OX}$-A binding equally, and $\mathrm{OX}-\mathrm{B}$ having $\sim 10$ fold selectivity for $\mathrm{OX}_{2} \mathrm{R}$. Although orexinergic neurons are localized to less than 100,000 hypothalamic neurons in the human brain, orexin receptors exhibit overlapping and distinct expression throughout the CNS, with significant expression in brain regions associated with arousal and vigilance state, as well as reward and stress processing.

Following their seminal discovery of this novel neuropeptide system 16 years ago, authors of the foundational Proc. Natl. Acad. Sci. and Cell papers joined by other exceptional researchers provide their latest insights into the function of orexin signaling and its therapeutic potential.

Drs. de Lecea and Huerta (2014) explain their current view on the interaction of orexin neurons with other neuromodulatory systems based on recent optogenetic experiments. A paper from Kohlmeier et al. (2013) presents an original investigation on the interaction of the orexin system with cholinergic and monoaminergic neurons using $\mathrm{OX}_{1}$ and $\mathrm{OX}_{2}$ receptor knockout mice. Two separate papers from Etori et al. (2014) and Tortorella et al. (2013) provide insight into potential synaptic interactions between the hypothalamus, locus coeruleus and oral pontine reticular nucleus, suggesting that orexin signaling within this circuit modulates stage succession during sleep-wakefulness cycles. Expanding upon the first observations of genetic disruptions of orexin receptors in dogs, Thompson et al. (2014) provide a pharmacogenetic overview of orexin peptides and their receptors, and describe the potential impact of polymorphisms observed in human genetic studies. Finally, work described in Flores et al. (2013) illustrates cannabinoid-hypocretin cross-talk within the CNS, an emerging area of interest for the field.

The identification of a neuropeptide system with restricted expression, key functions in fundamental CNS processes and approachability of discrete GPCR subtypes has made orexin receptors valuable targets for the next generation of CNS therapeutics, with multiple teams actively characterizing small molecules to understand the pharmacology and potential therapeutic applications of targeting the orexin system. Equihua et al. (2013) takes the reader on a journey comparing the merits and challenges of orexin receptor antagonists as potential sleep medications relative to currently used hypnotics. A paper from Callander et al. (2013) representing a team formerly at Novartis, provides substantial in vitro characterization and describes differential kinetic properties of dual orexin receptor antagonists (DORAs) that have undergone clinical evaluation. Two pharmacological papers from Morairty et al. (2014) (work by groups UCSF and SRI), and Ramirez et al. (2013) (Merck Research Laboratories), demonstrate that DORAs lack the impairment on motor and cognitive function in rodents exhibited by positive GABA-A receptor modulators. Etori et al. (2014) (Kanazawa University), Dugovic et al. (2014) (Janssen), and Hoyer et al. (2013) (team formerly at Novartis) explore the potential differential impact of DORAs as well as antagonists selective for $\mathrm{OX}_{1} \mathrm{R}$ and $\mathrm{OX}_{2} \mathrm{R}$ on non-REM and REM sleep architecture.

With regard to other potential indications for OXR antagonists beyond insomnia, two manuscripts from teams at Lilly Research Laboratories and MUSC (Anderson et al., 2014; Fitch et al., 2014) describe a novel $\mathrm{OX}_{2} \mathrm{R}$ selective antagonist, and its effects on rodent models of ethanol addiction and depression relative to a DORA and $\mathrm{OX}_{1} \mathrm{R}$ selective antagonist. In addition, (Steiner et al., 2013) (Actelion), investigated the impact of chronic pharmacological $\mathrm{OX}_{1} \mathrm{R}$ blockade in a rat model of diet-induced obesity.

A further area of orexin research which is being actively investigated focuses on the impact of orexin signaling on sympathetic autonomous nervous system activation, both during sleep and wake stages, as well as during heightened arousal and stress. Two excellent reviews from leaders in the field (Carrive, 2013; Li and Nattie, 2014) provide an overview of the current perspectives regarding cardiovascular and respiratory control by orexins. 
(Colas et al., 2014) present evidence supporting the existence of an orexin circuit between central and peripheral nervous system, where orexin signaling potentially modulates sensory processing at dorsal root ganglia.

Together with the increasing availability of pharmacological tools, investigations of the role of orexin in limbic emotional processing have also intensified during the last 3-4 years. Two detailed reviews shed light on this topic, from both academic and industry perspectives (Yeoh et al., 2014 from the University of Newcastle and the Hunter Medical Research Institute; Merlo Pich and Melotto, 2014, formerly of Glaxo Smith Kline). These two papers outline recent findings from rodent studies identifying involvement of orexins in mediating compulsive behavior, as well as panic, depression and anxiety-like reactions during withdrawal from drugs of abuse.

Importantly, this special issue highlights the exquisite foundational and translational work being conducted by teams at leading academic and biopharmaceutical laboratories, focused on investigating a range of therapeutic opportunities. Although it has only been 16 years since the identification of the orexin/hypocretin system, the wealth of knowledge obtained thus far has set the stage for the next decade of orexin research. It is with great appreciation to the contributing authors and with much enthusiasm that we present this special topics issue of Frontiers in Neuroscience.

\section{REFERENCES}

Anderson, R. I., Becker, H. C., Adams, B. L., Jesudason, C. D., and Rorick-Kehn, L. M. (2014). Orexin-1 and orexin-2 receptor antagonists reduce ethanol selfadministration in high-drinking rodent models. Front. Neurosci. 8:33. doi: 10.3389/fnins.2014.00033

Callander, G. E., Olorunda, M., Monna, D., Schuepbach, E., Langenegger, D., Betschart, C., et al. (2013). Kinetic properties of "dual" orexin receptor antagonists at OX1R and OX2R orexin receptors. Front. Neurosci. 7:230. doi: 10.3389/fnins.2013.00230

Carrive, P. (2013). Orexin, orexin receptor antagonists and central cardiovascular control. Front. Neurosci. 7:257. doi: 10.3389/fnins.2013.00257

Colas, D., Manca, A., Delcroix, J. D., and Mourrain, P. (2014). Orexin A and orexin receptor 1 axonal traffic in dorsal roots at the CNS/PNS interface. Front. Neurosci. 8:20. doi: 10.3389/fnins.2014.00020

de Lecea, L., and Huerta, R. (2014). Hypocretin (orexin) regulation of sleep-to-wake transitions. Front. Pharmacol. 5:16. doi: 10.3389/fphar.2014. 00016

de Lecea, L., Kilduff, T. S., Peyron, C., Gao, X., Foye, P. E., Danielson, P. E., et al. (1998). The hypocretins: hypothalamus-specific peptides with neuroexcitatory activity. Proc. Natl. Acad. Sci. U.S.A. 95, 322-327. doi: 10.1073/pnas.95.1.322

Dugovic, C., Shelton, J. E., Yun, S., Bonaventure, P., Shireman, B. T., and Lovenberg, T. W. (2014). Orexin-1 receptor blockade dysregulates REM sleep in the presence of orexin-2 receptor antagonism. Front. Neurosci. 8:28. doi: 10.3389/fnins.2014.00028

Equihua, A. C., De La Herrán-Arita, A. K., and Drucker-Colin., R. (2013). Orexin receptor antagonists as therapeutic agents for insomnia. Front. Pharmacol. 4:163. doi: $10.3389 /$ fphar.2013.00163

Etori, K., Saito, Y. C., Tsujino, N., and Sakurai, T. (2014). Effects of a newly developed potent orexin-2 receptor-selective antagonist, compound $1 \mathrm{~m}$, on sleep/wakefulness states in mice. Front. Neurosci. 8:8. doi: 10.3389/fnins.2014.00008

Fitch, T. E., Benvenga, M. J., Jesudason, C. D., Zink, C., Vandergriff, A. B., Menezes, M. M., et al. (2014). LSN2424100: a novel, potent orexin-2 receptor antagonist with selectivity over orexin-1 receptors and activity in an animal model predictive of antidepressant-like efficacy. Front. Neurosci. 8:5. doi: 10.3389/fnins.2014.00005

Flores, Á., Maldonado, R., and Berrendero, F. (2013). Cannabinoid-hypocretin cross-talk in the central nervous system: what we know so far. Front. Neurosci. 7:256. doi: 10.3389/fnins.2013.00256

Hoyer, D., Dürst, T., Fendt, M., Jacobson, L. H., Betschart, C., Hintermann, S., et al. (2013). Distinct effects of IPSU and suvorexant on mouse sleep architecture. Front. Neurosci. 7:235. doi: 10.3389/fnins.2013.00235

Kohlmeier, K. A., Tyler, C. J., Kalogiannis, M., Ishibashi, M., Kristensen, M. P., Gumenchuk, I., et al. (2013). Differential actions of orexin receptors in brainstem cholinergic and monoaminergic neurons revealed by receptor knockouts: implications for orexinergic signaling in arousal and narcolepsy. Front. Neurosci. 7:246. doi: 10.3389/fnins.2013.00246

Li, A., and Nattie, E. (2014). Orexin, cardio-respiratory function, and hypertension. Front. Neurosci. 8:22. doi: 10.3389/fnins.2014.00022

Merlo Pich, E., and Melotto, S. (2014). Orexin 1 receptor antagonists in compulsive behavior and anxiety: possible therapeutic use. Front. Neurosci. 8:26. doi: 10.3389/fnins.2014.00026

Morairty, S. R., Wilk, A. J., Lincoln, W. U., Neylan, T. C., and Kilduff, T. S. (2014). The hypocretin/orexin antagonist almorexant promotes sleep without impairment of performance in rats. Front. Neurosci. 8:3. doi: 10.3389/fnins.2014. 00003

Ramirez, A. D., Gotter, A. L., Fox, S. V., Tannenbaum, P. L., Yao, L., Tye, S. J., et al. (2013). Dual orexin receptor antagonists show distinct effects on locomotor performance, ethanol interaction and sleep architecture relative to gamma-aminobutyric acid-A receptor modulators. Front. Neurosci. 7:254. doi: 10.3389/fnins.2013.00254

Sakurai, T., Amemiya, A., Ishii, M., Matsuzaki, I., Chemelli, R. M., Tanaka, H., et al. (1998). Orexins and orexin receptors: a family of hypothalamic neuropeptides and $\mathrm{G}$ protein-coupled receptors that regulate feeding behavior. Cell 92, 573-585. doi: 10.1016/S0092-8674(00)80949-6

Steiner, M. A., Sciarretta, C., Pasquali, A., and Jenck, F. (2013). The selective orexin receptor 1 antagonist ACT-335827 in a rat model of diet-induced obesity associated with metabolic syndrome. Front. Pharmacol. 4:165. doi: 10.3389/fphar.2013.00165

Thompson, M. D., Xhaard, H., Sakurai, T., Rainero, I., and Kukkonen, J. P. (2014). OX1 and OX2 orexin/hypocretin receptor pharmacogenetics. Front. Neurosci. 8:57. doi: 10.3389/fnins.2014.00057

Tortorella, S., Rodrigo-Angulo, M. L., Núñez, A., and Garzón, M. (2013). Synaptic interactions between perifornical lateral hypothalamic area, locus coeruleus nucleus and the oral pontine reticular nucleus are implicated in the stage succession during sleep-wakefulness cycle. Front. Neurosci. 7:216. doi: 10.3389/fnins.2013.00216

Yeoh, J. W., Campbell, E. J., James, M. H., Graham, B. A., and Dayas, C. V. (2014). Orexin antagonists for neuropsychiatric disease: progress and potential pitfalls. Front. Neurosci. 8:36. doi: 10.3389/fnins.2014.00036

Conflict of Interest Statement: Michel Steiner is employed by Actelion Pharmaceuticals. Christopher Winrow is employed by Merck. Both companies are actively involved in the development of orexin receptor antagonists for clinical applications.

Received: 29 April 2014; accepted: 26 May 2014; published online: 12 June 2014. Citation: Steiner MA and Winrow CJ (2014) Opportunities and perspectives for developing orexin receptor antagonists. Front. Neurosci. 8:158. doi: 10.3389/fnins. 2014.00158

This article was submitted to Neuropharmacology, a section of the journal Frontiers in Neuroscience.

Copyright (c) 2014 Steiner and Winrow. This is an open-access article distributed under the terms of the Creative Commons Attribution License (CC BY). The use, distribution or reproduction in other forums is permitted, provided the original author(s) or licensor are credited and that the original publication in this journal is cited, in accordance with accepted academic practice. No use, distribution or reproduction is permitted which does not comply with these terms. 